Results Out of the 342 children from the rural area and 325 children from the urban area, 89 and 56 children were injured respectively in the last one year. The injuries resulted in a temporary impairment of $12.4 \%$ and $1.8 \%$ of children in rural and urban area respectively. Similarly, $11.2 \%$ of them in rural and $1.8 \%$ in the urban area suffered from some form of permanent disability. The children also missed their school ranging from 1 to 90 days due to injury. In $22.2 \%$ of injury cases in rural and $14.3 \%$ in the urban area, either of the parents had lost their workdays to take care of the injured child.

Conclusion The impacts of unintentional injuries were higher in rural areas, probably because of delays in seeking health care for the injury and lack of better health care facilities in the rural area.

Learning Outcomes There is a need of contextual and cost effective childhood injury prevention program to reduce premature mortality and morbidity (SDG 3.4).

\section{B.004 PREVENTING CHILDHOOD INJURIES IN UGANDA - DEVELOPMENT OF A CHILD SAFETY KIT}

${ }^{1}$ Prasanthi Puvanachandra* ${ }^{2}$ Charles Ssemugabo, ${ }^{2}$ Bonny Balugaba, ${ }^{2}$ Anthony Mugeere, ${ }^{3}$ Abdul Bachani, ${ }^{4}$ Rebecca Ivers, ${ }^{5}$ Adnan Ali Hyder, ${ }^{2}$ Olive Kobusingye, ${ }^{1}$ Margaret Peden. ${ }^{1}$ The George Institute for Global Health, Oxford University, Oxford, UK; ${ }^{2}$ Makerere University School of Public Health, Kampala, Uganda; ${ }^{3} J$ ohns Hopkins Bloomberg School of Public Health, Baltimore, USA; ${ }^{4}$ University of New South Wales, Sydney, Australia; ${ }^{5}$ Milken Institute School of Public Health, George Washington University, Washington DC, USA

10.1136/injuryprev-2021-safety. 127

Background Globally, nearly 650,000 children lose their lives to injuries every year. Injuries occurring in and around the home to children under 5 years (burns, falls, drowning, poisoning) can be prevented through providing safety equipment e.g. barriers, childproof containers. A number of studies have shown significant reductions in child injuries following this approach but all studies have thus far been conducted in high-income countries. Our research aims to reduce unintentional home injuries among under 5's in Jinja, Uganda through the provision of a child safety kit and parental education.

Methods This study is guided by a community-based participatory research (CBPR) approach utilizing mixed methods. A quantitative retrospective review of hospital data is combined with a community-based household survey and risk assessment checklist tool to provide incidence and risk factor data. A deeper exploration of attitudes and perceptions of injuries in the home along with participatory workshops is provided through focus-group discussions and Photovoice.

Results Data collection is currently underway and will be analysed between March-June 2020.

Conclusion This formative research will contextualize the problem and develop an intervention package including the child safety kit, educational material, parent training workshops and an awareness campaign. The findings will inform the development of a culturally appropriate/affordable safety kit and provide accurate incidence rates on which to base sample size calculations for an intervention trial to measure behaviour change and reductions in injuries.

Learning Outcomes The results will have significant implications for other low-income countries both in terms of research methodology and effectiveness information.
5C - Rural, March 24, 2021

\section{C.001 RURAL CRIME AS A HEALTH AND SAFETY ISSUE FOR SWEDISH ANIMAL FARMERS}

${ }^{1}$ Peter Lundqvist*, ${ }^{1}$ Eva Goransson, ${ }^{1}$ Catharina Alwall Svennefelt, ${ }^{2}$ Vania Ceccato, ${ }^{3}$ Hakan Johansson. 'Swedish University of Agricultural Sciences, Alnarp, Sweden; ${ }^{2} \mathrm{KTH}$ Royal Institute of Technology, Stockholm, Sweden; ${ }^{3}$ The Federation of Swedish Farmers LRF, Stockholm, Sweden

\subsection{6/injuryprev-2021-safety. 128}

Background Farmers with animal production in Sweden can experience different types of criticisms directed against their activities from consumers, the media and inspecting government agencies. On another level, threats, damage, tampering, robbery and other criminal acts are directed against the farm's activities, but also against the farmer, family members and employees. The farmers organization state the problems as a major health \& safety issue. The goal is to investigate the nature of the experiences of threats, crimes and criticism against animal production in Sweden.

Methods The research is achieved by assessing the consequences for individuals and farms, health, social and economic conditions. Interviews with farmers, web-based enquieries, data from official statistics and media coverage will underlie the methodology of this study. We focus on farmers not as 'victims' but rather as 'active agents', by illustrating ways that farmers handle, cope and respond to the criticisms and threats they are exposed in a daily basis.

Results Preliminary results of our ongoing research show that farmers of all types of animal production feel an increased level of worries and stress due to rural crime and external critizism. They also report that family members and employees are affected. Farmers try to cope with the new stress by investments in increased security measures at the farm, interacting more with other farmers, but also less public contacts.

Learning Outcomes It is obvious that rural crime and external critizism is adding further stress to the daily life of animal farmers and needs to be further investigated

\section{C.002 MULTIMILLION TRADE BY UNSKILLED ERGONOMIC- STRESSORS STRICKEN DATE PALM CLIMBERS IN RURAL SINDH}

${ }^{1}$ Khalid Mehmood*, ${ }^{2}$ Nazila Khalid*. 'Sindh Institute of Urology and Transplantation (siut), Karachi, Pakistan; ${ }^{2}$ The Recovery House, Karachi, Pakistan

10.1136/injuryprev-2021-safety. 129

Background The global date trade accounts $\$ 1.2$ billion and 8 billion trade of Pakistan, providing a major source of export revenues as well as of livelihood and income for 100,000 growers, farmers and exporters. The musculoskeletal disorders and occupational injuries being 2nd most common cause of disability measured by DALY (Disability Adjusted Life Years) to the global burden of disease and have emerged as a major challenge for developing countries in the SDGs era. Our study explored determinants and risk factors and affordable strategies for the treatment and rehabilitation in the date palm climber communities.

Methods A sequential mixed-methods study was conducted in rural areas of Sindh from March' to August'2019 using 